applications above, as well as to a variety of other structures, will be published in detail elsewhere.

D. H. S. HoRN

J. R. NUNN

W. S. RaPson

University of Cape Town. Aug. 8.

1 Baker, J. Chem. Soc., 258 (1945).

2 Linstead, Millidge, Thomas and WaIpole, J. Chem. Soc., 1146 (1937). Cf. Plattner, Furst and Jirasek, Helv. chim. Actr, 29 741 (1946).

${ }^{2}$ Wagner-Jauregg et al., Ber., 74, 1522 (1941).

'Cook, MeGinnis and Mitchell, J. Chem. Soc., 286 (1944).

\section{Coprecipitation of Uranous Sulphate with Rare-Earth Double Sulphates}

Sinoe uranous sulphate forms no double sulphate with sodium sulphate or the rare-earth sulphates which is insoluble in water or dilute sulphuric acid, it might be expected that tetravalent uranium would pass into the filtrates when the cerium group is separated from acid solutions of the sulphates as the double sodium sulphates. Certain cations not necess. arily tripositively charged, for example, $\mathrm{Th}^{4+}$, the ionic radii of which are close to those of the cerium group elements ${ }^{1}$, tend to be coprecipitated when this group is separated as double sodium sulphates ${ }^{2}$, although no corresponding insoluble double sulphates are known. The radius of the uranous ion, however, is almost equal to that of yttrium ${ }^{1}$, so there is added reason to expect tetravalent uranium in the soluble double-sulphate fractions. It has been found, on the contrary, that uranous sulphate in acid solution is either partly or wholly precipitated with cerium and the cerium group elements, the extent of coprecipitation depending mainly on the concentration of uranous and rare-earth ions. When the uranium concentration is sufficiently high, a pale green precipitate is obtained, the colour of which is more evident in artificial light.

The following figures were obtained by stirring anhydrous sodium sulphate into a solution of the composition: $\mathrm{Ce}_{2} \mathrm{O}_{3}, 32 \mathrm{gm} . / 1$; $\mathrm{UO}_{2}, 3.4 \mathrm{gm} . / 1$.; $\mathrm{H}_{2} \mathrm{SO}_{4}, 106 \mathrm{gm} . / 1$, and filtering after standing $30 \mathrm{~min}$. at $20^{\circ} \mathrm{C}$. Uranous sulphate was prepared by electrolytic reduction of uranyl sulphate at a lead cathode, air being blown through the solution before mixing in order to oxidize trivalent uranium ${ }^{3}$.

Mol. $\mathrm{Na}_{2} \mathrm{SO}_{4}$ per mol. of $\mathrm{Ce}_{2} \mathrm{O}_{3}$ $\mathrm{Ce}_{2} \mathrm{O}_{2}$ precipitated, per cent

$\begin{array}{llllll}\mathbf{1} \cdot 1 & 2 \cdot 2 & 3 \cdot 2 & 4 \cdot 3 & \mathbf{5} \cdot 4 & 6 \cdot 5 \\ \mathbf{7 2} & \mathbf{9 6} & 97 & 97 & 98 & 99 \\ \mathbf{3 4} & 71 & 85 & 92 & 95 & 97\end{array}$

When 6 mol. of sodium sulphate per mol. of $\mathrm{Ce}_{2} \mathrm{O}_{3}$ were added to a solution of the composition: $\mathrm{Ce}_{2} \mathrm{O}_{3}$, $24 \mathrm{gm}$./1. ; $\mathrm{UO}_{2}, 23 \mathrm{gm}$./1. ; $\mathrm{H}_{2} \mathrm{SO}_{4}, 200 \mathrm{gm}$./1. under the same conditions as before, 80 per cent of the uranous oxide and $99 \cdot 8$ per cent of the cerous oxide were precipitated. The weight fraction uranium oxide to uranium + cerium oxide in the precipitate was approximately $0 \cdot 43$. In a similar experiment with a sulphate solution of the composition : mixed rareearth oxides, $27 \mathrm{gm} . / 1$; $\mathrm{UO}_{2}, 2 \cdot 7 \mathrm{gm}$. $/$. ; $\mathrm{ThO}_{2}$, $3.2 \mathrm{gm} . / 1$; $\mathrm{H}_{2} \mathrm{SO}_{4}, 130 \mathrm{gm} . / 1$., 98 per cent of the uranous oxide and 98 per cent of the rare-earth oxides were precipitated by $6 \mathrm{~mol}$. of sodium sulphate.

An almost quantitative precipitation of uranous ion can thus be obtained at a rare-earth oxide concentration of not loss than $24-32 \mathrm{gm}$./1., provided that 98 per cent or more of the rare earths are precipitated and that the ratio of uranous oxide to rare earth oxides in solution is 0.1 or less. No significant amount of uranyl sulphate is coprecipitated with sodium cerium sulphate under similar experimental conditions. The precipitate is appreciably soluble in water, both uranous and rare-earth sulphates passing into solution; but the green colour of the precipitate cannot be removed by washing with water.

Earlier work ${ }^{2}$ with a solution of the composition: mixed rare-earth oxides, $30 \mathrm{gm} . / 1$. ; $\mathrm{ThO}_{2}, 3 \cdot 6 \mathrm{gm} . / 1$. ; $\mathrm{H}_{2} \mathrm{SO}_{4}, 109 \mathrm{gm}$./ 1 . has shown that only 46 per cent of the thoria is coprecipitated with the double sulphates by addition of $6 \mathrm{~mol}$. of sodium sulphate per mol. of mixed oxides. Quite large variations in acid concentration, temperature and time of standing had little effect on this result. There is thus only a qualitative resemblance between the coprecipitation of tetravalent uranium and thorium ions with rareearth double sulphates. The coprecipitation of thorium, however, is more understandable, since the radius of the thorium ion is some 5 per cent greater than that of the uranous ion and is approximately equal to that of gadolinium.

Although adsorption may play a part in the coprecipitation of uranium and thorium with sodium rare-earth sulphates, it is clear that other factors are involved besides ionic size or ionic charge and the solubility of the double sulphates in the system water-sodium sulphate - sulphuric acid. These must ultimately be traced to the different electronic structures of uranous, thorium and rare-earth ions.

A. W. WYLIE

\section{Division of Industrial Chemistry, \\ Council for Scientific and \\ Industrial Research, Melbourne. \\ 1 Hassel, O., trans. by R. C. Evans, “Crystal Chemistry", 11 (Heinemann, London, 1935). \\ 2 Pilkington, E. S., and Wylie, A. W., J. Soc. Chem. Ind., in the press. Kolthoff, I. M., and Lingane, J. J., J. Amer. Chem. Soc., 55, 1871 (1933).}

\section{Variation in Density of Cerium Oxide}

The existence of polymeric varieties of cerium oxide was proposed so long ago as $1897^{1}$, this contention being based, inter alia, upon the fact that the colour of the oxide is dependent, not only on its purity, but also upon the nature of the salt from which it is prepared by ignition. Although density figures quoted in standard text-books show obvious variation, I have been unable to trace any data correlating the density of cerium oxide prepared in different ways with the possibility of its existence in polymeric forms.

My starting material was cerium oxide of higher than 99.5 per cent purity, the remaining less than 0.5 per cent being other rare earth oxides. This was converted to sulphate with hot concentrated sulphuric acid, and then obtained in solution by diluting with water. Different portions of the sulphate solution thus obtained were then precipitated as oxalate, double sodium sulphate, and as hydroxide with ammonia. Two oxalate precipitates were converted to hydroxide and carbonate by digestion respectively with sodium hydroxide and carbonate; likewise with the double sodium salts. The carbonates and hydroxides were filtered off and washed free of alkalis and soluble salts. One oxalate precipitate was ignited as such, and a further portion of the initial sulphate solution evaporated to dryness and the sulphate thus obtained ignited. All specimenshydroxides, carbonates, oxalate and sulphate-were 